\title{
Total artificial heart: neurological complications
}

\author{
Lyle D. Joyce, David L. Joyce \\ Department of Surgery, Division of Cardiothoracic Surgery, Medical College of Wisconsin, Milwaukee, WI, USA \\ Correspondence to: Dr. Lyle D. Joyce. Department of Surgery, Division of Cardiothoracic Surgery, Medical College of Wisconsin, Milwaukee, WI, \\ USA. Email: ljoyce@mcw.edu.
}

Submitted Nov 28, 2019. Accepted for publication Feb 17, 2020.

doi: $10.21037 / a c s .2020 .02 .14$

View this article at: http://dx.doi.org/10.21037/acs.2020.02.14

Neurological complications following any surgical procedure have always been a dreaded outcome that no surgeon wishes to encounter. Many unique surgical techniques and protective devices have been designed to mitigate against such an occurrence, but despite these efforts, the rate of neurological problems in the mechanical circulatory support arena have remained frustratingly stable and higher than one would desire. No device is spared. The incidence of thromboembolic events in the first 100 total artificial hearts (TAH) implanted worldwide was $8.7 \%$ (four cerebrovascular accidents, five transient ischemic attacks) (1). This remained consistent with the next report at 176 patients having an overall stroke rate of $7 \%$ and transient ischemic attack 4\% (2). Arabia reported data from the interagency registry which included 450 patients from all centers in which 188 neurologic dysfunction events occurred. The incidence of stroke was $22.7 \%$ within the first 6 months. Overall, there were $13.5 \%$ ischemic and $10.2 \%$ hemorrhagic strokes (3).

This problem is not limited to the TAH. Like the TAH, first generation left ventricular assist devices (LVAD) were pulsatile pumps and incurred similar post-operative events. The incidence of stroke in the REMATCH trial was $16 \%$ (a pump with a textured surface) (4). The other LVADs showed comparable neurological events (12-32\%) (5). Moving to continuous flow (CF) devices did not solve the problem. In second-generation CF devices, such as the HeartMate II (Abbott; Pleasanton, CA, USA), the incidence of stroke is between $10 \%$ and $30 \%$, with a mean onset of 6-9 months after implantation (6). Longer follow-up studies have reported 5-year rates as high as $40 \%$ (7). In several case series, stroke is the leading cause of death in patients with CF-LVADs (8).
One could assume that perhaps heat from the bearings in LVADs contributed to the problem but even the thirdgeneration CF devices, such as the HeartWare VAD (Medtronic; Framingham, MA, USA) and the totally magnetic suspended bearingless HeartMate 3 (Abbott), continue to have a 1-year incidence of stroke as high as $18 \%(6,9)$.

Since changing the flow characteristics has had little impact on neurological outcomes, one must look to other possible factors that might come into play when implanting devices with large foreign body surface area interfacing with the blood stream, whatever the surfaces may be (polyurethane, smooth titanium, textured titanium).

The clinical correlation with strokes and infection continue to be an unresolved issue. If this relationship is key, we should see a sharp decline in neurological events once pumps become fully internalized. Even with no gross evidence of drive line infection, it is possible that patients get a bacteremia from time to time with line manipulation similar to the transient bacteremia observed with dental cleaning.

The HeartWare ENDURANCE trials demonstrated that tighter control of blood pressure does have an impact on neurological events. The incidence of stroke in HVAD subjects was reduced $24.2 \%$ in ENDURANCE Supplemental compared with ENDURANCE $(\mathrm{P}=0.10)$, and hemorrhagic cerebrovascular accidents were reduced by $50.5 \%(\mathrm{P}=0.02)(10)$. However, it did not eliminate neurological events completely.

The proinflammatory state that the body experiences with the introduction of foreign bodies in contact with the blood stream may alter the coagulation cascade to the point that neurological events are more likely. However, while the 
incidence may decrease progressively with time, it appears that one is never free of the risk.

Perhaps the new frontier for mechanical circulatory support devices is not to change the pump but to master a better understanding of the manipulation of the coagulation cascade. We know that all patients are not the same. Some are "bleeders" and some are "clotters". Will there be genetic testing that can identify which category a patient falls into even before the implant? We know our present laboratory tests are highly variable in sensitivity and specificity, however, we may not yet have the ideal tests available for managing this complex patient subset. Potentially, more accurate assessment will improve our ability to minimise both ischemic and hemorrhagic neurological events at the rate we currently experience.

During very early experiences with the TAH, we recognized that the group at Hôpital La Pitié Salpêtrière in France had much lower stroke rates than anyone in the US. The Tucson group spent several months in Paris learning their techniques of anticoagulation using drugs in some cases that weren't available in the US. This all points to the need for better understanding of the coagulation system.

Other evidence supports an association between hyperperfusion and the rapid restoration of cardiac output after device implantation. The first patient to receive the Jarvik 7 TAH as a destination device, seized when the cardiac output was pushed to a high level to avoid renal failure. Cerebral hyperperfusion syndrome is a known complication of carotid endarterectomy. A possible contributing condition is the impaired cerebrovascular autoregulation in chronic low-flow states. What relationship these situations have with post-implant neurological dysfunction is unknown.

Of course, we would desire a $0 \%$ rate of neurological events in this complex group of patients but the natural history of congestive heart failure shows that approximately $10-24 \%$ of patients with stroke have heart failure and heart failure appears to be the cause of stroke in $9 \%$ of the patients. While we may be able to rid the patient of heart failure from a physiological aspect, we still must deal with the multiple other risk factors that heart failure patients endure.

Although strokes are a dreaded complication in patients with TAHs, the literature would suggest that this incidence is certainly no greater (and perhaps less) than that seen in any of the LVADs. Much remains to be learned about the multiple variables that lead to this dreaded complication in the field of mechanical circulatory support.

\section{Acknowledgments}

None.

\section{Footnote}

Conflicts of Interest: The authors have no conflicts of interest to declare.

\section{References}

1. Joyce LD, Johnson KE, Toninato CJ, et al. Results of the first 100 patients who received Symbion Total Artificial Hearts as a bridge to cardiac transplantation. Circulation 1989;80:III192-201.

2. Johnson KE, Prieto M, Joyce LD, et al. Summary of the clinical use of the Symbion total artificial heart: a registry report. J Heart Lung Transplant 1992;11:103-16.

3. Arabia FA, Cantor, RS, Koehl, DA, et al. Interagency registry for mechanically assisted circulatory support report on the total artificial heart. J Heart Lung Transplant 2018;37:1304-12.

4. Lazar RM, Shapiro PA, Jaski BE, et al. Neurological events during long-term mechanical circulatory support for heart failure: the Randomized Evaluation of Mechanical Assistance for the Treatment of Congestive Heart Failure (REMATCH) experience. Circulation 2004;109:2423-7.

5. Copeland JG, Smith RG, Arabia FA, et al. Comparison of the CardioWest total artificial heart, the Novacor left ventricular assist system and the Thoratec ventricular assist system in bridge to transplantation. Ann Thorac Surg 2001;71:S92-7; discussion S114-5.

6. Tuncer ON, Kemaloglu C, Erbasan O, et al. Outcomes and readmissions after con-tinuous flow left ventricular assist device: Heartmate II versus Heartware ventricular assist device. Transplant Proc 2016;48:2157-61.

7. Stulak JM, Davis ME, Haglund N, et al. Adverse events in contemporary continuous-flow left ventricular assist devices: a multi-institutional comparison shows significant differences. J Thorac Cardiovasc Surg 2016;151:177-89.

8. Kirklin JK, Naftel DC, Pagani FD, et al. Seventh INTERMACS annual report: 15,000 patients and counting. J Heart Lung Transplant 2015;34:1495-504. 
9. Krabatsch T, Netuka I, Schmitto JD, et al. Heartmate 3 fully magnetically levitated left ventricular assist device for the treatment of advanced heart failure: 1-year results from the CE mark trial. J Cardiothorac Surg

Cite this article as: Joyce LD, Joyce DL. Total artificial heart: neurological complications. Ann Cardiothorac Surg 2020;9(2):121-123. doi: 10.21037/acs.2020.02.14
2017;12:23

10. Milano CA, Rogers JG, Tatooles AJ, et al. HVAD: The ENDURANCE Supplemental Trial. JACC Heart Fail 2018;6:792-802. 